Prepared in cooperation with the National Park Service and the State of Oklahoma, Oklahoma Water Resources Board

\title{
Helicopter Electromagnetic and Magnetic Geophysical Survey Data, Hunton Anticline, South-Central Oklahoma
}

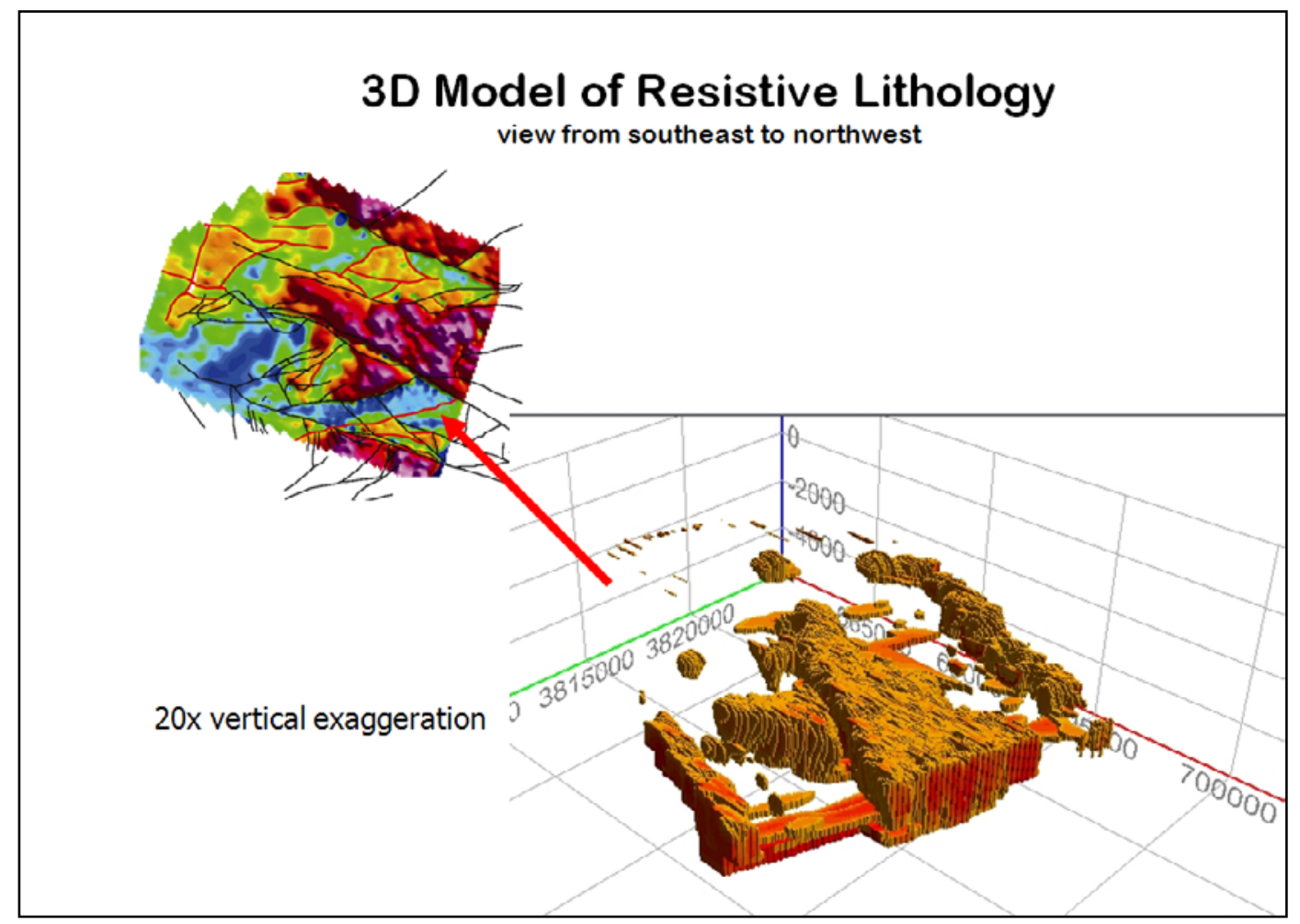

Open-File Report 2011-1240

U.S. Department of the Interior

U.S. Geological Survey 


\section{Helicopter Electromagnetic and Magnetic Geophysical Survey Data, Hunton Anticline, South-Central Oklahoma}

By Bruce D. Smith, David V. Smith, Maryla Deszcz-Pan, Charles D. Blome, and Patricia Hill

Prepared in cooperation with the National Park Service and the State of Oklahoma, Oklahoma Water Resources Board

Open-File Report 2011-1240 


\section{U.S. Department of the Interior \\ KEN SALAZAR, Secretary}

\section{U.S. Geological Survey \\ Marcia K. McNutt, Director}

U.S. Geological Survey, Reston, Virginia: 2011

For product and ordering information:

World Wide Web: http://www.usgs.gov/pubprod

Telephone: 1-888-ASK-USGS

For more information on the USGS—-the Federal source for science about the Earth, its natural and living resources, natural hazards, and the environment:

World Wide Web: http://www.usgs.gov

Telephone: 1-888-ASK-USGS

Any use of trade, product, or firm names is for descriptive purposes only and does not imply endorsement by the U.S. Government.

Although this report is in the public domain, permission must be secured from the individual copyright owners to reproduce any copyrighted material contained within this report.

Suggested citation:

Smith, B.D., Smith, D.V., Deszcz-Pan, Maryla, Blome, C.D., and Hill, Patricia, 2011, Helicopter electromagnetic and magnetic geophysical survey data, Hunton anticline, south-central Oklahoma : U.S. Geological Survey Open-File Report 2011-1240,15p.

COVER FIGURE: A three-dimensional model of electrically resistive lithology in flight block A. Upper left is apparent resistivity map at 115,000 hertz. Lower right is a voxel model of areas along flight lines having greater than $200 \mathrm{ohm}$ meters. 


\section{Contents}

Abstract

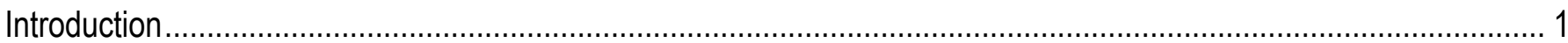

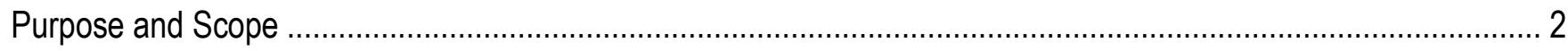

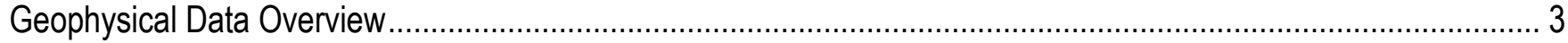

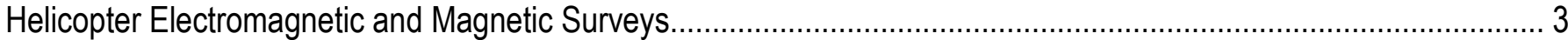

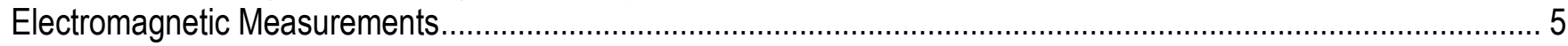

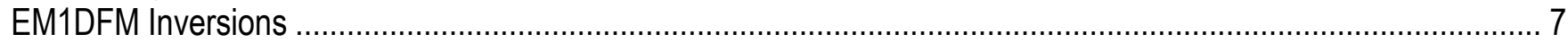

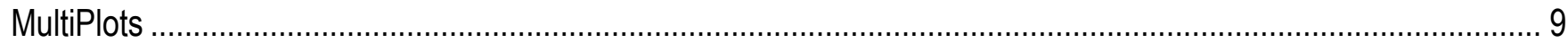

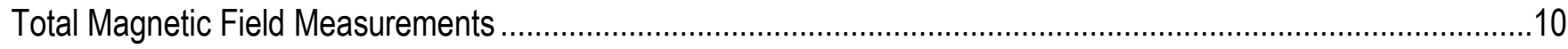

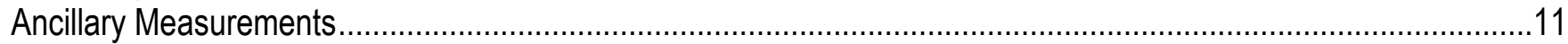

Digital Data

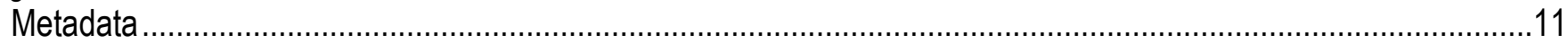

GIS Data

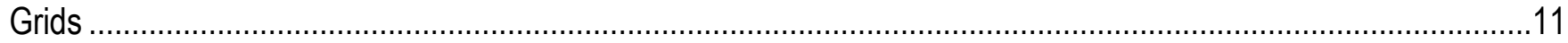

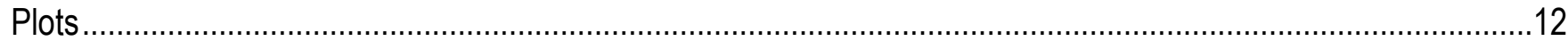

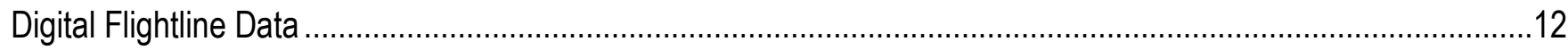

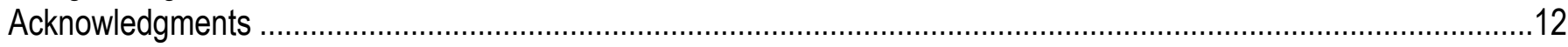

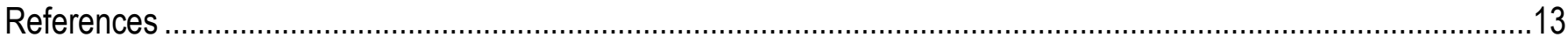

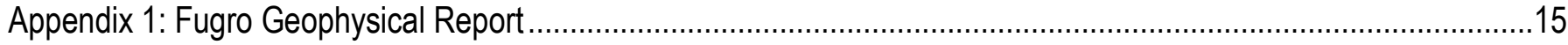

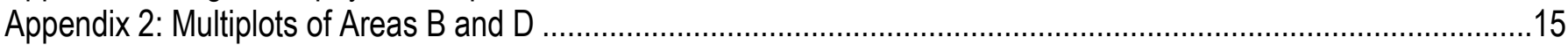

Appendix 3: 2007 Geological Society of America Annual Meeting Poster ..............................................................15

Appendix 4: 2008 American Geophysical Union Fall Annual Meeting Poster ...........................................................15

\section{Figures}

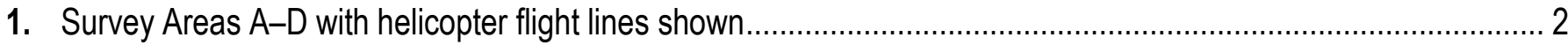

2. Helicopter-borne RESOLVE@ geophysical system used in the surveys ...................................................... 5

3. Depth of penetration or imaging as a function of frequency and Earth ...........................................................

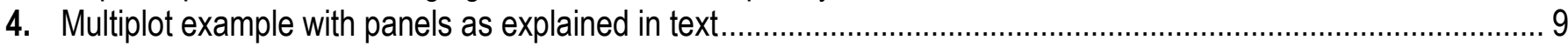

\section{Tables}

1. Description of data folders. Definitions used in table: GIS; geographic information system, Esri; Earth Resources Research Institute, ASCII; American Standard Code for Information Interchange. tif: tagged image format with geo prefix is georeferenced

2. Flightline direction and spacing for each survey area …........................................................................ 4

3. Frequencies and sensitivities for the HEM survey. The coil separation is 7.9 meters for all configurations

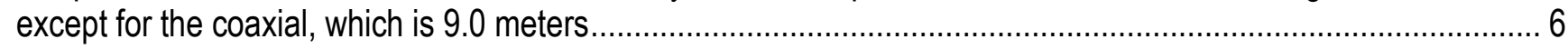

4. Layer thicknesses used for computation of resistivity depth sections from HEM line data ................................... 8 


\section{Conversion Factors, Datum, Acronyms, and Abbreviations}

SI to Inch/Pound

\begin{tabular}{lcll}
\hline \multicolumn{1}{c}{ Multiply } & By & To obtain \\
\hline Length & \\
\hline meter $(\mathrm{m})$ & 3.281 & foot $(\mathrm{ft})$ & \\
kilometer $(\mathrm{km})$ & 0.6214 & mile $(\mathrm{mi})$ & \\
square kilometer $\left(\mathrm{km}^{2}\right)$ & 247.1 & acre & \\
nanotesla $(\mathrm{nT})$ & 1 & gamma & \\
\hline
\end{tabular}

Temperature in degrees Celsius $\left({ }^{\circ} \mathrm{C}\right)$ may be converted to degrees Fahrenheit $\left({ }^{\circ} \mathrm{F}\right)$ as follows:

${ }^{\circ} \mathrm{F}=\left(1.8 \times{ }^{\circ} \mathrm{C}\right)+32$

Electrical resistivity is given in ohm-meters (ohm-m) unless otherwise specified.

Electrical conductivity is given in millisiemens per meter $(\mathrm{mS} / \mathrm{m})$ unless otherwise specified.

Vertical coordinate information is referenced to the "North American Vertical Datum of 1988 (NAVD 88)" except as noted in text.

Horizontal coordinate information is referenced to the "North American Datum of 1983, Universal Transverse Mercator Zone 14 (NAD 83 UTM Zone 14N)" except as noted in text.

Airborne geophysical survey used World Geodetic System of 1984 (WGS 84) for global positioning.

\section{Acronyms and Abbreviations}

$\begin{array}{ll}\text { CAT } & \text { Computer Aided Tomography } \\ \text { EM } & \text { Electromagnetic } \\ \text { DTM } & \text { Digital Terrain Model } \\ \text { GPS } & \text { Global Positioning System } \\ \text { HEM } & \text { Helicopter Electromagnetic } \\ \text { IGRF } & \text { International Geomagnetic Reference Field } \\ \text { JPG } & \text { Joint Photographic Experts Group file format } \\ \text { NAD 83 } & \text { North American Datum of 1983 } \\ \text { NAVD } & \text { North American Vertical Datum } \\ \text { OWRB } & \text { Oklahoma Water Resources Board } \\ \text { PDF } & \text { Portable Document Format file format } \\ \text { RTP } & \text { Reduction to the Pole } \\ \text { TDEM } & \text { Time Domain Electromagnetic } \\ \text { USGS } & \text { U.S. Geological Survey } \\ \text { UTM } & \text { Universal Transverse Mercator } \\ \text { WGS 84 } & \text { World Geodetic System of 1984 World Geodetic System of } 1984 \\ \text { Hz } & \text { hertz } \\ \text { kHz } & \text { kilohertz }\end{array}$




\title{
Helicopter Electromagnetic and Magnetic Geophysical Survey Data, Hunton Anticline, South-Central Oklahoma
}

\author{
By Bruce D. Smith, David V. Smith, Maryla Deszcz-Pan, Charles D. Blome, and \\ Patricia Hill
}

\begin{abstract}
This report is a digital data release for multiple geophysical surveys conducted in the Hunton anticline area of south-central Oklahoma. The helicopter electromagnetic and magnetic surveys were flown on March 16-17, 2007, in four areas of the Hunton anticline in south-central Oklahoma. The objective of this project is to improve the understanding of the geohydrologic framework of the Arbuckle-Simpson aquifer. The electromagnetic sensor for the helicopter electromagnetic survey consisted of six different transmitter-receiver orientations that measured the earth's electrical response at six distinct frequencies from approximately $500 \mathrm{Hertz}$ to approximately 115,000 Hertz. The electromagnetic measurements were converted to electrical resistivity values, which were gridded and plotted on georeferenced maps. The map from each frequency represents a different depth of investigation for each area. The range of subsurface investigation is comparable to the depth of shallow groundwater. The four areas selected for the HEM study, blocks A-D, have different geologic and hydrologic settings. Geophysical and hydrologic information from U.S. Geological Survey studies are being used by modelers and resource managers to develop groundwater resource plans for the Arbuckle-Simpson aquifer.
\end{abstract}

\section{Introduction}

Detailed geologic mapping and hydrogeologic characterization are necessary to delineate aquifers, assess their degree of hydrologic connection with streams and karst features, and better predict water quality and quantity.

Electrical geophysical methods can be used to image the subsurface of the earth using techniques similar to medical computer axial tomography (CAT) scans of the human body (Won, 1990). Airborne electrical geophysical methods have been used effectively by the U.S. Geological Survey (USGS) in a variety of groundwater resource projects and programs (Smith and others, 2007). An example is the helicopter electromagnetic (HEM) survey successfully used in the upper Seco Creek study area in the Edwards aquifer, Texas (Smith and others, 2003; Smith and others, 2008). The Edwards aquifer is a large limestone-hosted aquifer with karst development, and shares many similarities to the Arbuckle-Simpson aquifer (Faith and others, 2010). Structural and stratigraphic features observed in the HEM data were used to refine a three-dimensional EarthVision geologic model of the area which is described in Faith and others (2010). The airborne geophysical data for the areas flown in the area of the Hunton anticline (fig. 1) described in this report were collected by Fugro Airborne Surveys using a HEM system under contract to the USGS. The contractor's report, included as a PDF file (appendix 1), gives a more detailed description of 
the survey location. The digital airborne geophysical data collected along flightlines was processed by Fugro to produce digital maps. Additional data processing was completed by the USGS, and supplemental maps were produced. These digital line data and maps are included as part of the digital data release.

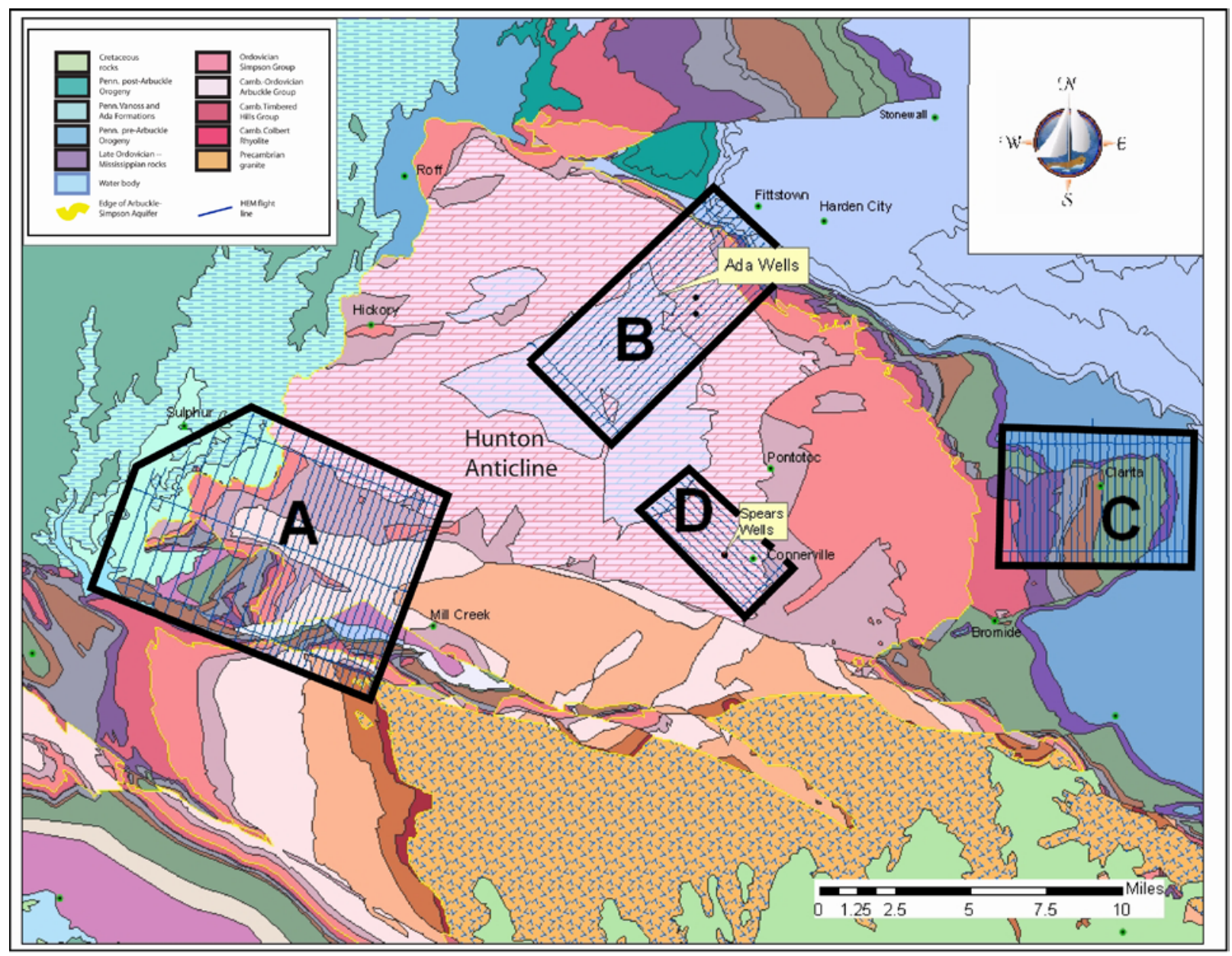

Figure 1. Survey Areas A-D with helicopter flight lines shown. The central red area is the limestone strata of the Hunton Anticline.

\section{Purpose and Scope}

Four separate survey areas (fig. 1) were chosen for evaluation of the HEM method in mapping geologic structure in the Arbuckle-Simpson aquifer in the Hunton anticline. This report presents maps of the HEM and magnetic data that were collected for the USGS by Fugro Airborne Surveys during March 16 and 17, 2007. The survey consisted of 770.3 line-kilometer, km (478.7 line-mile, mi). 


\section{Geophysical Data Overview}

The digital data from the airborne survey were acquired and processed by the contractor, Fugro Airborne Ltd., as described in appendix 1. The USGS did quality control of the contractor's data acquisition, processing, and report. In addition, the USGS provided some reprocessing of the data to meet specific requirements of this project. Both the contractor and USGS digital data are included in this data release. Links to the digital data and a brief description of the files and directories are provided in table 1. A more comprehensive discussion of the digital data is provided in the "Digital Data" section.

Table 1. Description of data folders. Definitions used in table: GIS; geographic information system, Esri; Earth Resources Research Institute, ASCII; American Standard Code for Information Interchange. tif: tagged image format with geo prefix is georeferenced.

\begin{tabular}{|l|l|}
\hline \multicolumn{1}{|c|}{ Folder } & \multicolumn{1}{c|}{ Content Description } \\
\hline METADATA & $\begin{array}{l}\text { Metadata description of digital data for geophysical grids for each flight block. Format is } \\
\text { generated from Geosoft Oasis montaj (http:/www.geosoft.com/). }\end{array}$ \\
\hline GIS & Flight path line plots as Esri shape files for each survey block. \\
\hline GRIDS & $\begin{array}{l}\text { Grids of the electromagnetic and magnetic field data for the horizontal coplanar coil } \\
\text { pairs. The grids are in Geosoft Oasis montaj ( } h \text { ttp:/www.geosoft.com/) format, a } \\
\text { standard of the geophysical industry used in many map display programs. }\end{array}$ \\
\hline LINEDATA & $\begin{array}{l}\text { Flightline data are in ASCll standard format. The "readme" file in this directory contains } \\
\text { a description of the channels of the digital line data. Data processing is described in } \\
\text { detail in the contractor's report in appendix 1. }\end{array}$ \\
\hline PLOTS & $\begin{array}{l}\text { Contains USGS and Fugro plots of gridded data in PDF and GeoTiff (UTM Zone 14N, } \\
\text { NAD 83 projected TIF files) formats. Each GeoTiff file has an associated world file: } \\
\text { TFW. The subfolder USGS/RDS, contains resistivity depth sections for each flight line } \\
\text { plotted in PDF format. }\end{array}$ \\
\hline REPORT & $\begin{array}{l}\text { This report and appendixes 1 through 4 are in this folder as PDF and Microsoft Word } \\
\text { files. }\end{array}$ \\
\hline
\end{tabular}

\section{Helicopter Electromagnetic and Magnetic Surveys}

Kirsh (2006), and Rubin and Hubbard (2005) provide overviews of geophysical principles and applications to groundwater studies. Airborne geophysical surveys are usually made along regularly spaced flightlines within each survey area (fig. 1). Flightlines can be as closely spaced as 50 meters $(\mathrm{m})$, although closer spacing is possible in special circumstances. The USGS has generally flown HEM surveys with 200-400 m spacing (1/8 to 1/4 mile: Smith and others, 2007), although flightlines with $800 \mathrm{~m}$ separation have been used to map regional structures in a carbonate aquifer setting (Smith and others, 2007). Wherever possible, flightlines are oriented perpendicular to the strike of geological features, such as faults. One objective of the present (2011) study is to evaluate the flightline spacing in terms of resolution of geohydrologic features in the eastern portion of the Hunton anticline (Block A, fig. 1). The flight line specifications for each survey area (fig 1) are provided in table 2. 
Table 2. Flightline direction and spacing for each survey area.

\begin{tabular}{|c|c|c|c|c|c|c|c|}
\hline $\begin{array}{c}\text { Survey } \\
\text { Block }\end{array}$ & $\begin{array}{c}\text { Traverse } \\
\text { line } \\
\text { azimuth } \\
(\mathrm{deg})\end{array}$ & $\begin{array}{c}\text { Tie } \\
\text { line } \\
\text { azimuth } \\
(\mathrm{deg})\end{array}$ & $\begin{array}{c}\text { Traverse } \\
\text { line } \\
\text { spacing } \\
(\mathrm{m})\end{array}$ & $\begin{array}{c}\text { Tie line } \\
\text { spacing } \\
(\mathrm{m})\end{array}$ & $\begin{array}{c}\text { Traverse } \\
\text { line } \\
\text { distance } \\
(\mathrm{km})\end{array}$ & $\begin{array}{c}\text { Tie line } \\
\text { distance } \\
(\mathrm{km})\end{array}$ & $\begin{array}{c}\text { Total } \\
\text { distance } \\
(\mathrm{km})\end{array}$ \\
\hline $\mathrm{A}$ & $19 / 199$ & $109 / 189$ & $400 / 800$ & 4,800 & 295.2 & 41.5 & 336.7 \\
\hline $\mathrm{B}$ & $44 / 224$ & $134 / 314$ & 400 & 12,000 & 179.3 & 11.6 & 190.9 \\
\hline $\mathrm{C}$ & $0 / 180$ & $90 / 270$ & 400 & 5,700 & 158.0 & 19.6 & 177.6 \\
\hline $\mathrm{D}$ & $132 / 312$ & $42 / 222$ & 400 & 6,500 & 58.6 & 6.5 & 65.1 \\
\hline \multicolumn{7}{r|}{} \\
\hline \multicolumn{7}{|r|}{} \\
\hline
\end{tabular}

The RESOLVEC HEM system was used for all of the surveys. The geophysical system, consisting of an electromagnetic transmitter and receiver, magnetometer, GPS (global positioning system), and a laser altimeter, is housed in a cylindrical tube, or bird, that is towed beneath the helicopter. The helicopter-borne instrumentation used for this survey is shown in figure 2 . In the system flown by Fugro Airborne, all of the measurements from the system are digitized at the bird and transmitted by way of a cable to a processing and digital recording system in the helicopter. Ten measurements of the geophysical data (electromagnetic, EM, and total field magnetic readings) are made every second, which, at a survey speed of 120 kilometers per hour $(\mathrm{km} / \mathrm{h})$, is equivalent to 1 sample every 3.3 meters along the flightline. 


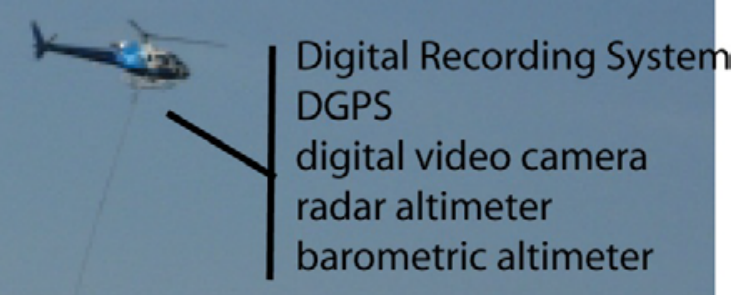

Magnetometer Laser Altimeter DGPS
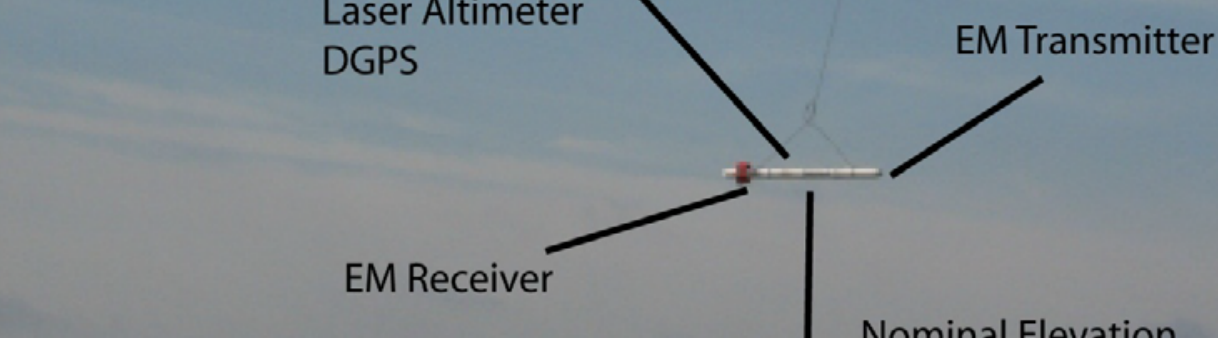

Nominal Elevation 30 to 40 meters

Magnetometer Base Station GPS base station

Figure 2. Helicopter-borne RESOLVEO geophysical system used in the surveys over the Hunton anticline. Electromagnetic, magnetic, GPS (global positioning system), and laser altimeter sensors are housed in a "bird", a cylindrical 9-meters-long tube, which is flown at about 30-40 meters above the earth's surface. DGPS is a digital global positioning system. (Photograph by Bruce D. Smith, USGS.)

\section{Electromagnetic Measurements}

The principles of HEM methods are summarized by Siemon (2006) and Paine and Minty (2005). The RESOLVEC HEM system flown by Fugro Airborne Surveys is described in detail in appendix 1. The EM measurements are made using six transmitter/receiver coil pairs that operate at separate frequencies from approximately $400 \mathrm{~Hz}$ to approximately $115 \mathrm{kHz}$. Five of the coil pairs are oriented in horizontal, coplanar positions, and one of the coil pairs is oriented in a vertical, coaxial orientation with respect to flightline bearing. The specific frequencies, separation, and orientation of the coil pairs are provided in table 3 . The nominal frequency is the one originally designed for the particular EM system used in this survey. The actual frequency was the specific frequency used in this survey as measured during system calibrations at the survey site. 
Table 3. Frequencies and sensitivities for the HEM survey. The coil separation is 7.9 meters for all configurations except for the coaxial, which is 9.0 meters.

\begin{tabular}{|l|c|c|l|}
\hline Coil Configuration & $\begin{array}{l}\text { Nominal } \\
\text { Frequency }(\mathrm{Hz})\end{array}$ & $\begin{array}{l}\text { Actual } \\
\text { Frequency }(\mathrm{Hz})\end{array}$ & $\begin{array}{l}\text { Sensitivity } \\
(\mathrm{ppm})\end{array}$ \\
\hline Coplanar & 385 & 380 & 0.12 \\
\hline Coplanar & 1,500 & 1,760 & 0.12 \\
\hline Coaxial & 3,300 & 3,270 & 0.12 \\
\hline Coplanar & 6,200 & 6,520 & 0.24 \\
\hline Coplanar & 25,000 & 26,640 & 0.60 \\
\hline Coplanar & 115,000 & 116,400 & 0.60 \\
\hline
\end{tabular}

The EM measurements along flight lines are reduced to apparent resistivity values as described in the contractor's report (appendix 1). One important consideration of earth subsurface imaging from HEM measurements is that the depth of imaging is dependent on the frequency and resistivity profile of the earth. One estimate of the depth of investigation (depth of mapping) for the frequencies used in the $\operatorname{RESOLVE}^{\mathcal{O}}$ system is shown in figure 3 . In this figure, the depth of exploration is defined as one-half of the skin depth (the point at which a plane electromagnetic wave has attenuated to 37 percent of the initial amplitude). The depths of investigation estimates shown in figure 4 are conservative, since one skin depth is considered to be the depth limit of HEM measurements (Fraser, 1978). For typical shallow earth materials, depths of investigation at the highest frequency are just a few meters. At the lowest frequency, $400 \mathrm{~Hz}$, the depth of investigation may be on the order of $100 \mathrm{~m}$. This aspect of HEM resistivity measurements is the basic principle that allows depth images to be constructed (Rubin and Hubbard, 2005).

An important part of the data processing is leveling the EM signals for system drift and calibration corrections. The specific steps used in the data processing are described in appendix 1 .

The digital line data (.XYZ files in the LINEDATA folder) provides the raw in-phase and quadrature data and the processed data from which the apparent resistivities are computed. The final leveled data also are provided. These data are included in the database, in case the original data are needed for reprocessing. Images of the EM data for blocks A and C are shown in the GSA poster in appendix 3. Images of the EM data for blocks A-D are shown in the AGU poster in appendix 4 . This poster also discusses the mapping of epikarst using the EM data. 


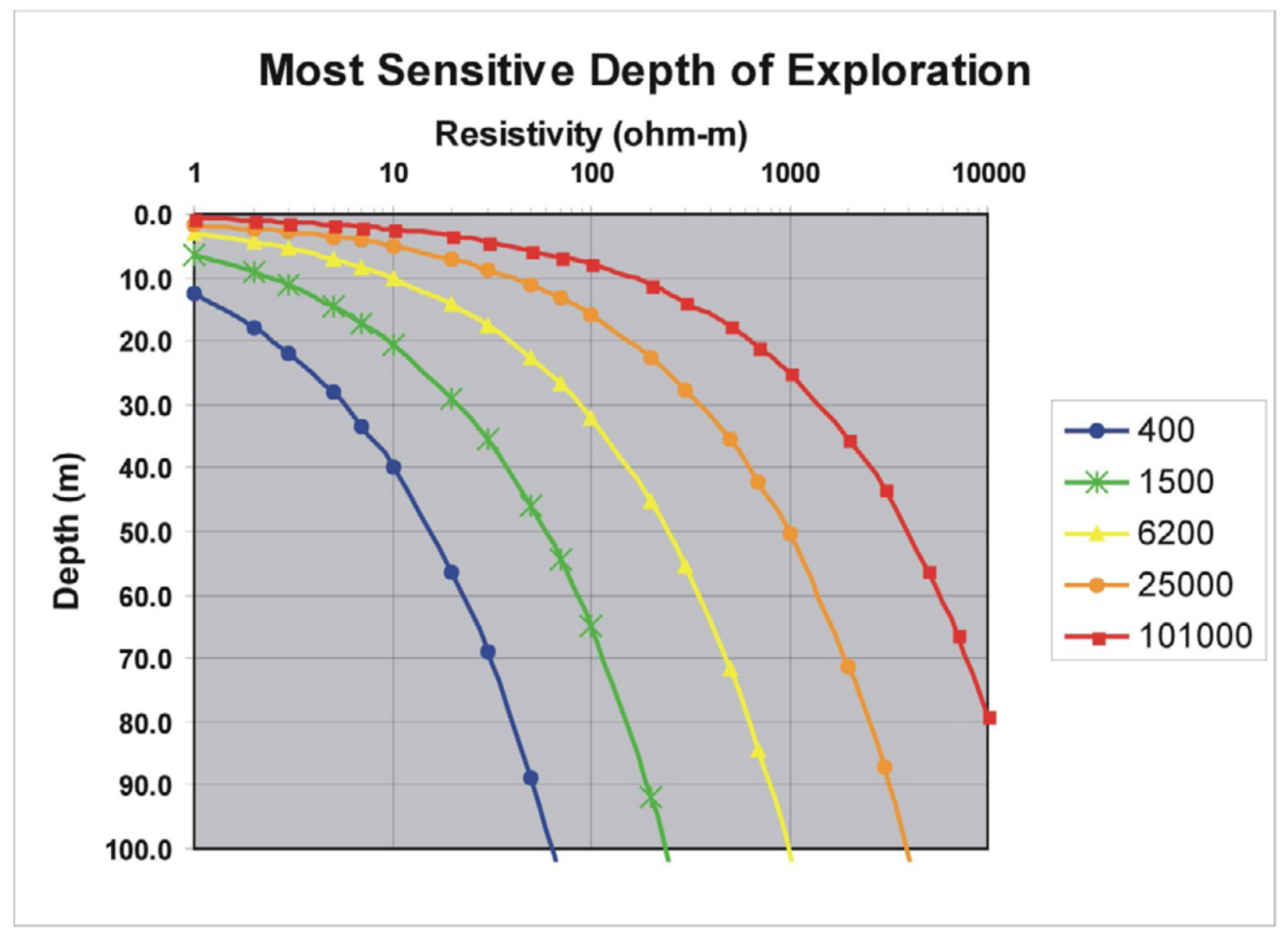

Figure 3. Depth of penetration or imaging as a function of frequency and Earth resistivity for the RESOLVEC system (Hodges, Fugro Airborne, 2004).

\section{EM1DFM Inversions}

Hodges (2004) gives a good overview of inversion methods for HEM data. In this study, the program EM1DFM (Farquharson and Oldenburg, 2004) was used to do one dimensional (1-D) layered earth inversions on the HEM flight line data. This type of inversion is usually termed imaging since the number of layers is more than the number of frequencies at which measurements are made. This program inverts for resistivities of a user-specified number of layers with fixed, user-specified thicknesses that are constant throughout the survey. Application of this type of resistivity imaging in karst terrains was developed to interpret an HEM survey of the Edwards aquifer in the north Seco Creek area in south-central Texas (Smith and others, 2003). The layer thickness used for the HEM inversion of the Hunton anticline data is provided below in table 4 . The last layer is a uniform half space. The resistivity depth images (RDI) can be plotted along flight lines as electrical cross sections. 
Table 4. Layer thicknesses used for computation of resistivity depth sections from HEM line data.

\begin{tabular}{|r|r|r|r|}
\hline Upper & Lower & Thickness & Midpoint \\
\hline 0 & -1.01 & 1.01 & 0.505 \\
\hline-1.01 & -2.15 & 1.14 & 1.58 \\
\hline-2.15 & -3.44 & 1.3 & 2.795 \\
\hline-3.44 & -4.91 & 1.47 & 4.175 \\
\hline-4.91 & -6.58 & 1.67 & 5.745 \\
\hline-6.58 & -8.47 & 1.89 & 7.525 \\
\hline-8.47 & -10.61 & 2.14 & 9.54 \\
\hline-10.6 & -13.04 & 2.43 & 11.825 \\
\hline-13.0 & -15.79 & 2.75 & 14.415 \\
\hline-15.8 & -18.92 & 3.12 & 17.355 \\
\hline-18.9 & -22.46 & 3.54 & 20.69 \\
\hline-22.5 & -26.47 & 4.02 & 24.465 \\
\hline-26.5 & -31.03 & 4.56 & 28.75 \\
\hline-31.0 & -36.19 & 5.17 & 33.61 \\
\hline-36.2 & -42.05 & 5.86 & 39.12 \\
\hline-42.1 & -48.7 & 6.64 & 45.375 \\
\hline-48.7 & -56.23 & 7.53 & 52.465 \\
\hline-56.2 & -64.77 & 8.54 & 60.5 \\
\hline-64.8 & -74.46 & 9.69 & 69.615 \\
\hline-74.5 & -85.45 & 10.99 & 79.955 \\
\hline-85.5 & -97.91 & 12.46 & 91.68 \\
\hline-97.9 & -112.0 & 14.13 & 104.975 \\
\hline-112 & -128.1 & 16.02 & 120.05 \\
\hline-128 & -146.2 & 18.17 & 137.145 \\
\hline-146 & -166.8 & 20.61 & 156.535 \\
\hline-167 & -190.2 & 23.37 & 178.525 \\
\hline-190 & -216.7 & 26.50 & 203.46 \\
\hline
\end{tabular}




\section{MultiPlots}

The results of the processing (profiles and RDIs) have been presented using Profile Analyst software (Encom Technology Pty. Ltd., 2008), with a horizontal scale of 1:24000 on 24"x 36 " plots. The horizontal X scale on every plot is in either UTM Easting or UTM Northing, depending on the angle of the flight line with true north. If this angle is less than or equal to $45^{\circ}$, then the UTM units are Northing; if this angle is greater than $45^{\circ}$, then the X coordinate represents Easting. A MultiPlot is a standard layout of HEM data and output on a single plotter sheet that was developed by Condor Consulting (written commun., 2004). The contents of a MultiPlot are described below. A single example of a MultiPlot from Block B is shown in figure 4. Appendix 2 contains the Multiplots for Block B and Block D.

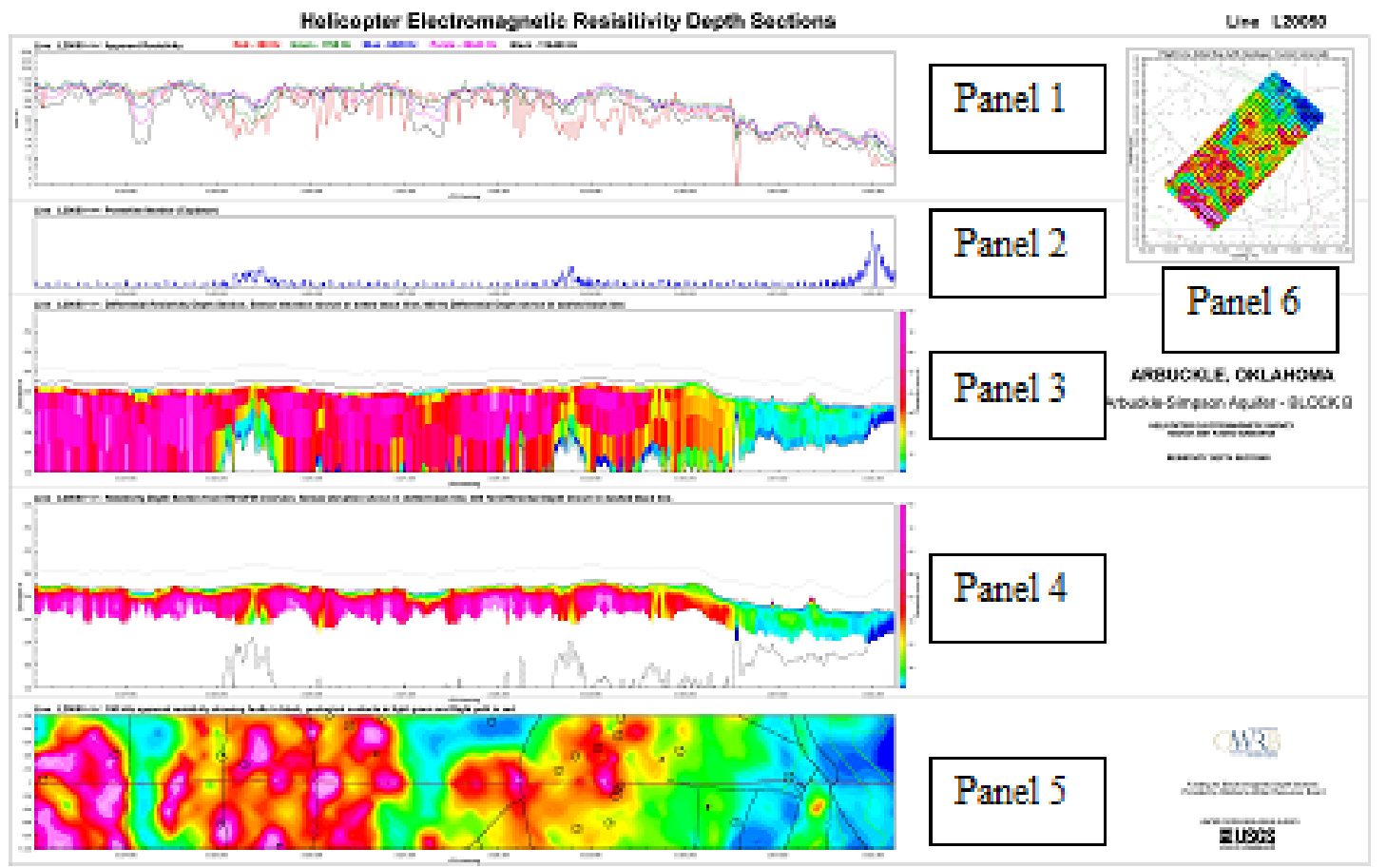

Figure 4. Multiplot example with panels as explained in text.

Panel 1 - Apparent Resistivities: This panel shows profiles of the pseudo-layer half-space apparent resistivities for the five coplanar coil pairs, as calculated and supplied by Fugro. Values are in ohm-meters and are plotted on a logarithmic vertical scale. The resistivity values differ for each frequency, as the lowest frequency has the greatest depth of penetration and the highest frequency has the least penetration.

Panel 2 - Powerline Monitor: The $60-\mathrm{Hz}$ powerline channels for both coaxial and coplanar coils were recorded during the survey, and the coplanar $60-\mathrm{Hz}$ signal is shown in this panel using a linear scale of $0-10$ for Blocks B and D. The powerline monitor channel can be used as a diagnostic: anomalies in apparent resistivities coincident with 
spikes in this channel are subject to close evaluation for quality assurance.

Panel 3 - Differential Resistivity-Depth Section: This panel contains the resistivity sections based on differential parameters. The vertical axis is elevation above sea level in meters and has 400-m elevation span for Blocks B and D. Differential resistivity values at each coplanar frequency are plotted at the corresponding differential depth. The vertical depth extent is limited between the $100-\mathrm{kHz}$ and $400-\mathrm{Hz}$ differential depths with the remaining frequencies interpolated in between. The sections are not extrapolated to the surface resulting in the white, no-data area near the surface. The resistivities in the resistivity-depth section have been plotted using a stretched color scale to represent resistivity values, with a consistent range of 10-800 ohm-m for Blocks B and D. The topography is indicated by the black solid line. To enable easy recognition of how well the helicopter has draped the topography, the height of the RESOLVE bird above the ground is indicated by the thin black-dotted-line profile above topography.

Panel 4 - Resistivity-Depth Section: This panel contains the RDI sections from the EM1DFM inversion. The resistivities in the resistivity-depth section have been plotted using the same vertical, horizontal, and color scales as in the differential depth sections. The bottom of the RDI sections have been truncated at the DOI, as discussed in section 3.0 above. To facilitate comparison with differential RDI (panel 3), the differential-depth at $400 \mathrm{~Hz}$ (the lowest operational frequency) is also plotted as a dotted black line below the inverted section. The height of the RESOLVE bird above the ground is indicated by the thin black-dotted-line profile above topography.

Panel 5 - Geological contacts and faults superimposed on 100-kHz apparent resistivity grid: This shows a plan view of the apparent resistivity and superimposed geologic map features (same scale as the profiles) as a strip along the flight line, with the latter shown as the red line approximately centered in the panel. The purpose of this presentation is to enable quick and easy correlation of features observed on the profiles with geological features, and vice versa.

Panel 6 - Flight Line Index Map (top right of MultiPlot page): This shows (at small scale) all the lines of the survey, overlain on the $100-\mathrm{kHz}$ apparent-resistivity grid with geologic contacts for reference. The current line displayed is highlighted in red, to indicate its location within the survey area.

\section{Total Magnetic Field Measurements}

The magnetic field consists of the earth's main magnetic field and the local magnetic field because of magnetized lithologies within the crust and magnetized metallic sources near the surface. The system measures the earth's total magnetic field to an accuracy of 0.01 nanotesla (nT). The total field measurements are affected by short-term variations in the main magnetic field, which are independent of local sources and are caused mainly by currents in the ionosphere. A magnetic field base station, set up by the contractor near the base of operations, is used to record these short-term variations in the total magnetic field, which are subtracted from the measurements made during the survey.

The contractor also processed the total magnetic field to remove the spatial variation from the earth's main magnetic field. This spatial variation is defined by the International Geomagnetic Reference Field or IGRF. Sharma (2002) describes the basic principles of the main magnetic field removal from magnetometer measurements.

Additional processing steps were applied by the USGS to the magnetic field data to reduce the data to the magnetic north pole and to filter out large-scale trends. Reduction to the pole (RTP) shifts magnetic highs to coincide with the magnetic source. The RTP and high-pass filtering were 
completed using Oasis montaj software (Geosoft, Inc., 2009). Images of the magnetic data for blocks A-D are shown in the GSA poster in appendix 3. Images of the magnetic data for blocks A$\mathrm{C}$ are shown in the AGU poster in appendix 4.

\section{Ancillary Measurements}

The HEM system monitors $60-\mathrm{Hz}$ signals in coaxial and coplanar coil configurations provided as CXPL and CPPL channels in the line database (LINEDATA folder). The data are provided as arbitrary voltage levels, which generally increase in the vicinity of power lines. The expression of power lines is quite variable because of a number of factors such as the size of the line, how well it is grounded, and the electrical resistivity of the earth. In general, the infrastructure around urban development, transmission towers, and along major roads has a higher cultural noise level, resulting in high $60-\mathrm{Hz}$ signals. The HEM system also monitors electrical noise from lightning (spheric or atmospheric noise; Sharma, 2002) and is recorded in the channel labeled CPSP in the line database (LINEDATA folder).

Positioning measurements of the bird and the helicopter are critical in processing and making accurate maps. Location data from the GPS system in the bird and helicopter are provided in the files in the LINEDATA folder. Elevation data from the laser altimeter on the bird, as well as the radar and barometric altimeters on the helicopter, are provided in the LINEDATA folder. An important aspect of the contractor's data processing is that the elevation data are provided in the WGS 84 (http://en.wikipedia.org/wiki/WGS84) reference ellipsoid and have NOT been reduced to the geoid. The contractor's report explains that additional processing needed to do this data reduction was not part of the USGS contract.

\section{Digital Data}

Digital data links are provided in the directories described in table 1. The following describes the digital data in each subdirectory.

\section{Metadata}

The METADATA directory contains files that describe each of the four geophysical survey blocks (fig. 1) and the digital grids described below. These survey blocks are the boundaries for line data, digital grids, and plots. The metadata also describes the projection used for all of the digital plots, which is NAD 83, UTM Zone 14N (meters). The metadata follows the standards of the federal geographic data committee (http://www.fgdc.gov/metadata/ accessed June, 2010) and is given in GEOSOFT Oasis monaj XML (extensible markup language) files.

\section{GIS Data}

The GIS folder contains flight line location files as Environmental Systems Research Institute (Esri) shape files (http://www.esri.com/library/whitepapers/pdfs/shapefile.pdf; accessed June, 2010), which have been grouped in .ZIP files for each flight block.

\section{Grids}

Flight line data are interpolated into a regular grid in order to produce digital map plots. One of the challenges of gridding airborne geophysical data is that the spacing between flight lines (hundreds of meters) is much greater than the sampling along the line (a few meters). Specialized 
gridding methods have been developed to deal with this aspect of processing airborne geophysical data. The contractor has used a modified Akima spline method (appendix 1, also see

http://www.geosoft.com/resources/papers/pdfs/topicsingriddingworkshop.pdf) developed as part of their in-house data processing software. The contractor grids are provided as links in the GRIDS/FUGRO subdirectory. These grids have not been modified. The nomenclature for the grid names is provided in the a readme.txt file.

An alternate gridding method is the minimum curvature method (http://www.geosoft.com/resources/papers/pdfs/topicsingriddingworkshop.pdf accessed on June 9, 2010) implemented in the Oasis montaj program:

This algorithm was used to produce grids from selected channels of the flight line data. These data are found in the GRIDS/FUGRO and GRIDS/USGS folders. File naming convention is provided in the GRIDS FUGRO FOLDER CONTENTS.doc and GRIDS USGS FOLDER CONTENTS.doc files.

\section{Plots}

The contractor provided plots for each survey area of the apparent resistivity data at each frequency and plots of the IGRF-corrected total magnetic field. These plots are provided as PDF files in the PLOTS/FUGRO folder (table 1). Note that for the apparent resistivity, the color scales have been stretched for each frequency to emphasize the maximum (red) and minimum (blue) range. Consequently, the color scales are not directly comparable between maps with different frequencies. The plots were made from the data as gridded by the contractor using methods described in the project report (appendix 1).

The USGS has created plots of the gridded data as georeferenced TIF format (GeoTiff) plots. These plots also are provided as PDF files in PLOTS/USGS folder (table 1). The projection used for the GeoTiff plots is the same as the grids, NAD 83, UTM Zone 14N. The GeoTiff images have been made as both flat color (CLR) files and as color-shaded relief images (CSR). The color scale for all of the resistivity maps is the same and provided as the resistivity_scale.png file. The color scale shows high resistivity as warm colors (reds) and low resistivity as cool colors (blues). Color scales for the magnetic and digital elevation maps also are provided as bitmap JPG files.

\section{Digital Flightline Data}

The flightline data for each area are provided in the LINEDATA folder. The files are provided in ASCII format with column headings as described in the 'readme file'. The contractor's report in appendix 1 also describes the digital flightline data.

\section{Acknowledgments}

The USGS Mapping Program provided base funding for the airborne survey. The authors would like to thank Bruce Heise and Jennifer Back of the National Park Service for contributing funds for in-fill flight lines in Area A, which borders the Chickasaw National Recreation Area on the east. The authors would like to thank Noel Osborn of the Oklahoma Water Resources Board for funding detailed analysis and interpretation of Areas B and D, which encompass municipal water supply wells and a research borehole. 


\section{References}

Encom Technology Party Ltd., 2008, Users guide, profile analyst version 8: North Sydney, Australia, $174 \mathrm{p}$.

Faith, J.R., Blome, C.D., Pantea, M.P., Puckette, J.O., Halihan, Todd, Osborn, Noel, Christenson, Scott, and Pack, Skip, 2010, Three-dimensional geologic model of the Arbuckle-Simpson aquifer, south-central Oklahoma, U.S. Geological Survey Open-File Report 2010-1123, 26 p.

Fraser, D.C., 1978, Resistivity mapping with an airborne multicoil electromagnetic system: Geophysics, v. 43, p. 144-172.

Geosoft, Inc., 2009, Oasis Montaj users manual version 7.2, 297 p, accessed June 10, 2010, at http://www.geosoft.com/resources/tutorials/.

Hodges, Greg, 2004, Practical inversions for helicopter electromagnetic data: Proceedings Symposium on the Application of Geophysics to Engineering and Environmental Problems, Environmental and Engineering Geophysical Society, 10 p.

Kirsch, Robert, 2006, Groundwater geophysics-A tool for hydrogeology: Berlin, Springer-Verlag, $489 \mathrm{p}$.

Paine, J.G. and Minty, B.R.S., 2005, Airborne hydrogeophysics, in Rubin, Yoram, and Hubbard, S. S.,eds., Hydrogeophysics: The Netherlands, Springer, Water Science and Technology Library, v. 50, p. 333-357.

Rubin, Yorham. and Hubbard, S.S., 2005, Hydrogeophysics: The Netherlands, Springer, Water Science and Technology Library, v. 50, 523 p.

Sharma, P.V., 2002 (reprinted), Environmental and engineering geophysics: Cambridge, England, University Press, $472 \mathrm{p}$.

Siemon, Bernhard, 2006, Electromagnetic methods - frequency domain: Airborne techniques, in: Kirsch, R., ed., Groundwater geophysics - A tool for hydrogeology: Berlin, Heidelberg, Springer-Verlag, p. 155-170.

Smith, B.D., Grauch, V.J.S., McCafferty, A.E., Smith, D.V., Rodriguez, B.R., Pool, D.R., DeszczPan, M., and Labson, V.F., 2007, Airborne electromagnetic and magnetic surveys for groundwater resources: A decade of study by the U.S. Geological Survey, in, Milkereit, B., ed., Proceedings of Exploration 07: Fifth Decennial International Conference on Mineral Exploration, p. $895-899$. 
Smith, B.D., Irvine, Richard, Blome, C.D., Clark, A.K., and Smith, D.V., 2003, Preliminary results, helicopter electromagnetic and magnetic survey of the Seco Creek area, Medina and Uvalde counties, Texas: Proceedings for the Symposium on the Application of Geophysics to Environmental and Engineering Problems, San Antonio, Texas, 15 p.

Smith, D.V., Smith, B.D., Blome, C.D., and Osborn, Noel, 2008, Airborne and ground electrical surveys for subsurface mapping of the Arbuckle qquifer, Central Oklahoma, American Geophysical Union Annual Meeting, San Francisco, 1 p.

Smith, D.V., Deszcz-Pan, Maryla, and Smith, B.D., 2009, Depth section imaging for portions of an airborne geophysical survey of the Hunton anticline, south-central Oklahoma final administrative report to the Oklahoma Water Resources Board in fulfillment of the cooperative agreement \#08C7OK002032407, accessed November 11, 2011, at http://www.owrb.ok.gov/studies/groundwater/arbuckle_simpson/pdf/2009_Reports/DepthSectionI magingAirborneGeophysicalSurveyHuntonAnticline_SmithDeszczPanSmith.pdf.

Won, I.J., 1990, Diagnosing the Earth: Ground-water Monitoring Review: Summer 1990, National Ground Water Association, v. 10, no. 3, p. 5-8. 


\section{Appendix 1: Fugro Geophysical Report}

The contractor's report (FugroReport.pdf) is provided in the $\underline{R E P O R T}$ folder.

\section{Appendix 2: Multiplots of Areas B and D}

Smith and others (2009) give detailed analysis and interpretation of resistivity-depth inversions, emphasizing geologic structure and epikarst. Multiplots of resistivity depth sections are given in this appendix provided in the $\underline{R E P O R T}$ folder.

\section{Appendix 3: 2007 Geological Society of America Annual Meeting Poster}

The poster entitled Preliminary Results of Airborne and Ground Resistivity Surveys for Subsurface Mapping in the Hunton Anticline South-Central Oklahoma by David V. Smith, Bruce D. Smith, Charles D. Blome, Todd Halihan, and Jennifer Back, is provided as two PDF files (GSAposter_panel01.pdf, GSAposter_pane102.pdf) in the $\underline{R E P O R T}$ folder.

\section{Appendix 4: 2008 American Geophysical Union Fall Annual Meeting Poster}

The poster H51G-0933 by David V. Smith, Bruce D. Smith, Charles D. Blome, and Noel Osborne, entitled Airborne and Ground Electrical Surveys for Subsurface Mapping of the Arbuckle-Simpson Aquifer, Central Oklahoma, is provided as three PDF files (H51G9033_panel01.pdf, H51G-9033_pane102.pdf, H51G-9033_panel03.pdf) in the $\underline{R E P O R T}$ folder. 